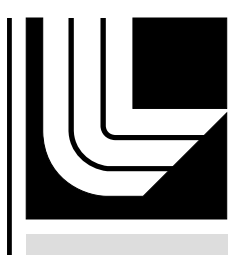

LAW RENCE LIVERMORE N A TIO NAL LABORATORY

\title{
Toward a Deeper Understanding of Plutonium
}

A. J. Schwartz, W. G. Wolfer

June 21, 2007

Journal of Computer-Aided Materials Design 
This document was prepared as an account of work sponsored by an agency of the United States Government. Neither the United States Government nor the University of California nor any of their employees, makes any warranty, express or implied, or assumes any legal liability or responsibility for the accuracy, completeness, or usefulness of any information, apparatus, product, or process disclosed, or represents that its use would not infringe privately owned rights. Reference herein to any specific commercial product, process, or service by trade name, trademark, manufacturer, or otherwise, does not necessarily constitute or imply its endorsement, recommendation, or favoring by the United States Government or the University of California. The views and opinions of authors expressed herein do not necessarily state or reflect those of the United States Government or the University of California, and shall not be used for advertising or product endorsement purposes. 
Guest Editors' Preface

\section{Toward a Deeper Understanding of Plutonium}

Plutonium is a very complex element lying near the middle of the actinide series. On the lower atomic number side of $\mathrm{Pu}$ is the element neptunium; its $5 f$ electrons are highly delocalized or itinerant, participating in metallic-like bonding. The electrons in americium, the element to the right of $\mathrm{Pu}$, are localized and do not participant significantly in the bonding. Plutonium is located directly on this rather abrupt transition. In the low-temperature $\alpha$ phase ground state, the five $5 f$ electrons are mostly delocalized leading to a highly dense monoclinic crystal structure. Increases in temperature take the unalloyed plutonium through a series of five solid-state allotropic phase transformations before melting. One of the high temperature phases, the close-packed face centered cubic $\delta$ phase, is the least dense of all the phases, including the liquid. Alloying the $\mathrm{Pu}$ with Group IIIA elements such as aluminum or gallium retains the $\delta$ phase in a metastable state at ambient conditions. Ultimately, this metastable $\delta$ phase will decompose via a eutectoid transformation to $\alpha+\mathrm{Pu}_{3} \mathrm{Ga}$. These low solute-containing $\delta$-phase $\mathrm{Pu}$ alloys are also metastable with respect to low temperature excursions or increases in pressure and will transform to a monoclinic crystal structure at low temperatures via an isothermal martensitic phase transformation or at slightly elevated pressure.

The delocalized to localized $5 f$ electron bonding transition that occurs in the light actinides surrounding $\mathrm{Pu}$ gives rise to a plethora of unique and anomalous properties but also severely complicates the modeling and simulation. The development of theories and models that are sufficiently sensitive to capture the details of this transition and capable of elucidating the fundamental properties of plutonium and plutonium alloys is currently

a grand challenge in actinide science. Recent advances in electronic structure theory, semi-empirical interatomic potentials, and raw computing power have enabled remarkable progress in our abilities to model many of the anomalous properties of $\mathrm{Pu}$. This special issue of the Journal of Computer-Aided Materials Design highlights a number of these advances in the area of the aging of plutonium.

This aging is a long-term process due to the slow radioactive decay with a long half-life of 24400 years for the major isotope of plutonium. The challenge then is to predict the changes in properties of plutonium and its alloys from experimental results of plutonium aged only for a few decades and from theory and computational models that are build on a thorough, first-principle understanding of all the complex phenomena displayed by this material. We hope that progress and success of this enterprise will guide other endeavors in Computer-Aided Materials Design and prediction of materials performance.

This work was performed under the auspices of the U.S. Department of Energy by University of California, Lawrence Livermore National Laboratory under Contract W-7405-Eng-48. 